\title{
ADEQUAÇÃO TECNOLÓGICA DE FRUTOS DA AMAZÔNIA: LICOR DE ARAÇÁ-BOI (Eugenia stiptata) McVAUGH
}

\author{
Jerusa de S. ANDRADE', Francisca C. F. RIBEIRO², Carlos G. ARAGÃO, \\ Sidney A. do N. FERREIRA'
}

\begin{abstract}
RESUMO - Para avaliar o potencial do araçá-boi para produção de licores, foi estudada a composição química da polpa e o efeito de alguns parâmetros do processamento, tais como, tipo de líquido extrator, tempo de maceração, proporção polpa/liquido extrator, proporção xarope/extrato e método de preparo do xarope. $\mathrm{O}$ araçá-boi apresentou boas caracteristicas para o processamento de licor, como o pH ácido, altos teores de acidez titulável, sólidos solúveis e carotenóides totais. Os parâmetros ideais para obtenção de licor de boa qualidade foram: cinco dias de maceração na proporção de 1:2 (p/v) de polpa:álcool de milho, relação de $1: 0,5(\mathrm{v} / \mathrm{v})$ de xarope:extrato na formulação, utilizando-se xarope preparado com dissolução do açúcar sob aquecimento.
\end{abstract}

Palavras-chave: fruto tropical, Eugenia stipitata, composição quimica, obtenção de licor, avaliação serfsorial.

\section{Suitability of Amazonian Fruit: Araçá-Boi (Eugenia stiptata McVaugh) for Liquor Production}

ABSTRACT - The potemial of araça-boi for liquor processing was studied through fruit pulp composition and the effect of processing parameters, such as: extraction liquid type, maceration time, pulp/extraction liquid ratio, proportion of syrup/extract and syrup processing method. The araçá-boi presents good characteristics for liquor processing, such as, acidic pH, high titrable acidity, soluble solids and total carotenoids contents. For the araçá-boi liquor processing the optimized parameters were: five days for maceration time; $1: 2(\mathrm{~g} / \mathrm{ml})$ of pulp/extraction liquid ratio at maceration; the $1: 0.5(\mathrm{ml} / \mathrm{ml})$ of syrup/extract ratio at the formulation; preparation of the syrup using heat; utilization of the corn alcohol. With this conditions, a good product is obtained.

Key-words: tropical fruit, Eugenia stipitata, fruit chemical composition, liquor processing, sensory evaluation.

\section{INTRODUÇÃO}

Na Bacia Amazônica, há um grande número de espécies frutíferas, dentre as quais destaca-se o araçá-boi (Eugenia stiptata McVaugh), consumido na forma de sucos, sorvetes e cremes (CLEMENT \& SILVA FILHO, 1994). $\mathrm{O}$ fruto tem alto rendimento em polpa e características ideais para industrialização (ANDRADE et al., 1989).

O licor é classificado entre as "Bebidas Alcoólicas por Mistura" sendo definido como "bebida com a graduação alcoólica de 18 a $54^{\circ} \mathrm{GL}$ (graus Gay Lussac) obtida pela mistura ou redestilação do álcool etílico potável ou aguardente simples desodorizada, com substância de origem vegetal ou animal, adicionada de sacarose, glicose, mel ou xarope de glicose" (SOLER, 1993).

A fabricação artesanal de licores de frutos é normalmente realizada por dois métodos: a) aquecimento da polpa com açúcar eágua, retirada das partículas sólidas e adição da substância alcoólica; b) maceração da polpa com substância alcoólica, retirada das partículas sólidas

\footnotetext{
1 Instituto Nacional de Pesquisas da Amazônia, Caixa postal 478, 69011-970 - Manaus, Amazonas, Brasil.

2 PIBIC/CNPq/INPA

3 Pós-graduação FEA/UNICAMP, Campinas, São Paulo, Brasil.
} 
e agregação de xarope. Em alguns casos, é necessário a clarificação (com carvão animal ou albumina) para retirada de substâncias coloidais responsáveis pela turvação do licor.

Esta pesquisa teve como objetivo verificar a potencialidade do araçá-boi para a fabricação de licores.

\section{MATERIAL E MÉTODOS}

Para a avaliação das características químicas, foram colhidos frutos na maturação comercial, procedentes de 14 plantas da área central, dentre as 48 cultivadas no campus V-8 do Instituto Nacional de Pesquisas da Amazônia (INPA). Foram realizadas colheitas semanais durante os meses de agosto a dezembro. O número de frutos em cada colheita variou de 1 a 5 frutos/ planta, dependendo do grau de maturação e produção.

Após a retirada das sementes, os frutos foram triturados em liquidificador formando uma amostra homogênea. As análises de umidade, $\mathrm{pH}$, sólidos solúveis e acidez titulável foram realizadas no mesmo dia da colheita. O restante da amostra triturada foi congelado e estocado em freezer para as demais avaliações.

As determinações de umidade (em estufa com circulação de ar, regulada a $65^{\circ} \mathrm{C}$ ), matéria seca, $\mathrm{pH}$, acidez titulável, sólidos solúveis, pectina (como pectato de cálcio) e ácido ascórbico (redução do 2,6diclorofenolindofenol) seguiram metodologias descritas por RANGANNA (1986). O teor de carotenóides totais foi obtido segundo HIGBY (1962). A extração dos compostos fenólicos foi feita com metanol 50\% segundo GOLDSTEIN
\& SWAIN (1963) e o doseamento pelo método de Folin-Denis descrito por SCHANDERL (1970). O extrato aquoso foi analisado quanto aos açúcares redutores e totais (após a hidrólise ácida) pelo método de Somogy Nelson, descrito por SOUTHGATE (1976). Os não redutores foram obtidos por diferença.

Para o processamento dos licores, os frutos foram colhidos no estádio de maturação comercial, independente das plantas. Após a seleção, lavagem, secagem e retirada das sementes, foram triturados em liquidificador. As polpas foram acondicionadas em sacos plásticos (capacidade de I $\mathrm{Kg}$ ), congeladas e estocadas em freezer até a fabricação dos licores.

Nos experimentos foram testados o efeito do tipo de líquido extrator (aguardente, vodka, álcool de cana de açúcar e álcool de milho), da proporção entre a quantidade de polpa e o líquido extrator $(1: 1,1: 2$, e $1: 3 \mathrm{~g} /$ $\mathrm{ml})$, do tempo de maceração $(5,10 \mathrm{e}$ 15 dias) e da proporção entre o xarope e o extrato $(1: 0,5,1: 1$ e $1: 2 \mathrm{ml} / \mathrm{ml})$ na confecção final dos licores. Foram estudados também dois processos de obtenção do xarope, isto é, xarope obtido por dissolução do açúcar com ou sem aquecimento. Foi utilizada a proporção de 2:1 (açúcar:água) e filtragem imediata em algodão. $\mathrm{O}$ aquecimento foi feito em banho-maria a $90^{\circ} \mathrm{C}$ por 10 minutos e a filtragem dentro de estufa (para o xarope preparado sob aquecimento). Através de um grupo de 25 provadores, foram observadas as características de coloração, limpidez e "flavor". As melhores condições de processamento 
e formulação foram adotadas para elaboração do licor que foi avaliado quanto a aceitabilidade pelo teste hedônico com escala de nove categorias, segundo WATTS et al. (1989).

\section{RESULTADOS E DISCUSSÃO}

As análises da composição da polpa (Tab. 1) demonstraram ser o araçá-boi um fruto suculento com baixo conteúdo de matéria seca, o que indica sua adequação para produtos como sucos, néctares, geléias e licores. Apresenta baixo $\mathrm{pH}$ e acidez elevada. A relação Brix/acidez indica o baixo grau de doçura do fruto, o que limita seu consumo na forma "in natura"; porém, o sabor ácido é característica desejável na formulação de produtos como sucos e licores, pois, proporciona, respectivamente, fator de diluição elevado e sabor acentuado.

Os sólidos solúveis corresponderam a $70,30 \%$ da concentração de sólidos totais. A concentração dos açúcares totais corresponde a apenas $49,42 \%$ dos sólidos solúveis, levemente superior a dos ácidos orgânicos, equivalente a $45,76 \%$. Os açúcares não redutores foram majoritários em relação aos redutores, sendo ambos presentes em pequenas quantidades.

Quando maduro, o araçá-boi apresenta intensa coloraçâo amarela. No entanto, outros pigmentos amarelos, não extraidos pela metodologia empregada estão presentes no fruto e permaneceram retidos no residuo da extração. Comparado com outros frutos, a concentração de compostos fenólicos é baixa. As

Tabela 1. Composição quimica média da polpa de araçá-boi (Eugenia stiptata McVaugh) em estadio de maturação comercial.

\begin{tabular}{|c|c|}
\hline Constituintes & Concentraçäo $^{1}$ \\
\hline Umidade $^{2}$ & 91,48 \\
\hline Matéria seca² & 8,52 \\
\hline $\mathrm{pH}$ & 2,66 \\
\hline Acidez titulável em ácido cítrico² & 2,73 \\
\hline Sólidos solúveis ( ${ }^{\circ} \mathrm{Brix}$ ) & 5,99 \\
\hline Relação Brix/acidez & 2,10 \\
\hline Açucares redutores ${ }^{2}$ & 0,99 \\
\hline Açucares não redutores ${ }^{2}$ & 1,97 \\
\hline Açucares totais ${ }^{2}$ & 2,96 \\
\hline Pectato de cálcio ${ }^{2}$ & 0,63 \\
\hline Ácido ascórbico ${ }^{3}$ & 35,21 \\
\hline Carotenóides totais ${ }^{3}$ & 0,48 \\
\hline Compostos fenólicos ${ }^{3}$ & 130,21 \\
\hline \multicolumn{2}{|c|}{$\begin{array}{l}\text { Média de } 210 \text { determinaçōes correspondentes a } 14 \text { plantas } \\
\text { analisadas semanalmente, em triplicata, durante cinco meses } \\
\text { (agosto a dezembro) }\end{array}$} \\
\hline${ }^{3}=m g, 100 g^{-1}$ & \\
\hline
\end{tabular}


substâncias pécticas não apresentaram concentração suficiente para exercer efeito negativo na limpidez do licor obtido com extrato de álcool de milho.

Foram observadas variações na composição quimica do araçá-boi em função da planta analisada. Os resultados de umidade, $\mathrm{pH}$, pectato de cálcio, ácido ascórbico, carotenóides totais e compostos fenólicos foram inferiores e os de acidez, sólidos solúveis, relação Brix/acidez e açúcares superiores aos valores de composição química de araçá-boi proveniente de plantio em outra localidade (ANDRADE et al., 1989). Essas diferenças mostram a influência das condições ambientais, procedência das plantas e tratos culturais na composição química do fruto.

O álcool de milho apresentou melhor capacidade de extração (Tab. 2), obtendose extrato de coloração amarelo canário forte, limpido e com acentuado "flavor" do fruto. Os demais apresentaram esses parâmetros pouco acentuados, além da turbidez e do forte odor de álcool (extrato de álcool comum).

Não foram detectadas diferenças na aparência, coloração e "flavor" do fruto em função do tempo de maceração. Porém, como o menor tempo de processamento implica em redução de custos, o período de cinco dias pode ser indicado para a extração nas condições adotadas. A proporção ideal de polpa/álcool de milho foi de 1:2. A de 1:3 influenciou negativamente na coloração e a de 1:1 no rendimento do extrato (Tab. 3).

A dissolução do açúcar sob aquecimento foi o melhor processo de obtenção do xarope, o qual, além da rapidez na dissolução do açúcar, apresentou coloração amarelada, devido ao processo de caramelização.

Tabela 2. Efeito do líquido extrator nas características dos extratos para formulação de licor de araçá-boi.

\begin{tabular}{llll}
\hline Extrator & Aparência & "Flavor"1 & Coloração \\
\hline Álcool comum & Turva & Fraco & Amarelo claro \\
Aguardente & Turva & Fraco & Amarelo claro \\
Vodka & Turva & Fraco & Amarelo bem claro \\
Álcool de milho & Límpida & Acentuado & Amarelo forte \\
\hline
\end{tabular}

= "Flavor" do fruto detectado no extrato.

Tabela 3. Efeito da proporção polpa/liquido extrator na qualidade do licor de araçá-boi'.

\begin{tabular}{llll}
\hline \multirow{2}{*}{ Parâmetros } & \multicolumn{3}{c}{ Proporção polpa/liquido extrato $(\mathrm{g} / \mathrm{ml})$} \\
\cline { 2 - 4 } & \multicolumn{1}{c}{$1: 1$} & $1: 2$ & $1: 3$ \\
\hline "Flavor"do fruto & Acentuado & Acentuado & Acentuado \\
Aparência & Límpida & Límpida & Límpida \\
Coloração & Amarelo forte & Amarelo forte & Amarelo claro \\
\hline
\end{tabular}

1 Licor obtido com álcool de milho, 5 dias de maceração e proporção de 1:2 (polpa/liquido extrator) e 1:0,5 (xarope/extrato) 
Tabela 4. Resultado da análise sensorial do licor de araçá-boi'.

\begin{tabular}{lccc}
\hline \multirow{2}{*}{ Gategorias } & \multicolumn{3}{c}{ Proporção xarope:extrato $(\mathrm{v} / \mathrm{v})$} \\
\cline { 2 - 4 } & $1: 0,5$ & $1: 1$ & $1: 2$ \\
\hline Gostei extremamente & 72 & 16 & 24 \\
Gostei muito & 24 & 40 & 24 \\
Gostei moderadamente & 0 & 20 & 24 \\
Gostei ligeiramente & 4 & 20 & 0 \\
Indiferente & 0 & 0 & 0 \\
Desgostei ligeiramente & 0 & 4 & 28 \\
Desgostei moderadamente & 0 & 0 & 0 \\
Desgostei muito & 0 & 0 & 0 \\
Desgostei extrememente & 0 & 0 & 0 \\
\hline
\end{tabular}

${ }^{1}$ Licor obtido com álcool de milho, 5 dias de maceração e proporção de 1:2 (polpa/líquido extrator)

A análise sensorial mostrou que $o$ licor de araça-boi é saboroso, de coloração atraente e odor característico do fruto. O licor formulado com a proporção de 1 de xarope para 0,5 de extrato obteve $100 \%$ de aceitação. Observa-se que a formulação de $1: 1$ obteve $96 \%$ de aceitação, porém, com resultados dispersos entre as categorias da faixa de aceitação. A proporção de 1:2 foi caracterizada como muito forte, apesar da boa aceitação pelos provadores (Tab. 4).

\section{CONCLUSÕES}

$\mathrm{O}$ araçá-boi apresentou boas características para o processamento de licor, como o $\mathrm{pH}$ ácido e altos teores de acidez, sólidos solúveis e carotenóides totais. A análise sensorial indicou como de melhor qualidade, o licor formulado através da extração com álcool de milho na proporção de $1: 2$ (polpa:líquido extrator) macerado por 5 dias e o uso de xarope preparado por aquecimento na proporção de 1:0,5 (xarope:extrato).

\section{Bibliografaia Citada}

ANDRADE, J.S.; ARAGÃO, C.G.; CHAAR, J.S.; LEÃO, I.M.S. 1989. Caracterização do araçá-boi (Eugenia stiptata McVaugh, subsp. sororia). In: CONGRESSO BRASILEIRO DE CIÊNCIA E TECNOLOGIA DE ALIMENTOS, 12., Rio de Janeiro, Resumos, SBCTA, p. 87.

CLEMENT, C.R.; SILVA FILHO, D.F. 1994.Amazonian small fruits with commercial potential. Fruit Varieties Journal, 48(3):152-158

GOLDSTEIN, J.L; SWAIN, T. 1963. Changes in tannins in ripening fruits. Phytochemistry, 2:371-383.

HIGBY, W.K. 1962. A simplified method for determination of some aspects of the carotenoid distribution in natural and carotene-fortified orange juice. Journal of Food Science, 27(1):42-49.

RANGANNA, S. 1986. Analysis and quality control for fruits and vegetable products. New Delhi, Tata Mc GrawHill Publishing, 1112 p.

SCHANDERL, S.H. 1970. Tannins and related phenolics. In: JOSLYN, M.A. (ed). Methods in food analysis. New York, Academic Press, p. 701-725.

SOLER, P.M. 1993. Como fazer licor. Brasília, IBICT, $23 \mathrm{p}$.

SOUTHGATE, D.A.T. 1973. Determination of 
food carbohydrates. London, Applied Science Publishing, $178 \mathrm{p}$.

WATTS, B.M.; YLIMAKI, G.L.; JEFFERY, L.E.; ELIAS, L.G. 1989. Basic senscry methods for food evaluation. Ottawa, IDRC, p. 66-79. 